\title{
Аспекты эффективности и успешности соревновательной деятельности теннисистов
}

\author{
Мингалимова А.Р. ${ }^{1}$, Мутаева И.Ш. ${ }^{*}$, Коновалов И.Е., Гизатуллина Ч.А. ${ }^{3}$ \\ ${ }^{1}$ Поволжская государственная академия физической культуры, спорта и туризма \\ Казань, Россия \\ ORCID: oooo-ooo3-4479-2794, albinausmanova@rambler.ru \\ ORCID: oOoo-O003-2953-1975, igko2006@mail.ru \\ ${ }^{2}$ Елабужский институт (филиал) Казанского (Приволжского) федерального университета \\ г. Елабуга, Россия \\ ORCID: oOoo-ooo2-9387-7033, mutaeva-i@mail.ru* \\ ${ }^{3}$ Набережночелнинский государственный педагогический университет \\ Набережные Челны, Россия \\ ORCID: oooo-ooo2-8563-3207, mutaeva-ma@yandex.ru
}

\begin{abstract}
Аннотация: В статье рассматриваются теоретические и практические аспекты построения соревновательной подготовки юных теннисистов. Развитие тенниса как вида спорта сопровождается неуклонным ростом международной конкуренции на соревнованиях различного уровня. Отмечено повышение зрелищности и популярности данного вида спорта среди детей и подростков. Теннис привлекает молодёжь эффективной скоростной техникой и востребованностью разносторонней физической подготовки. Основная тенденция развития современного тенниса характеризуется с позиции совершенствования технических и тактических приемов в игре. Повышается эффективность и востребованность скоростной игры, при этом продолжается совершенствование тактики игры на основе совершенствования существующих технико-тактических действий. Методъ $\boldsymbol{u}$ материал исследования. Анализ-научно-методической литературы, анкетный опрос специалистов с целью выявления основных факторов, определяющих эффективность соревновательной подготовки теннисистов. Проведено педагогическое наблюдение за игрой высококвалифицированных теннисистов с записью в журнале регистрации технических и тактических действий. Определены особенности проведения тренировочных занятий, активность и эффективность игроков за игру и количество технико-тактических действий. Резулътатъ. Теоретический анализ показал зависимость результативности выступлений теннисистов на соревнованиях от скорости и темпа игры при выполнении большого объёма технико-тактических действий. Определены значимые параметры соревновательной деятельности теннисистов. Представлена эффективность техникотактических действий в соревновательной деятельности теннисистов в динамике нескольких спортивных сезонов. Выявлены основные факторы, требующие их учета при обучении юных теннисистов. Заключение. Для ведения успешной соревновательной деятельности к теннисисту предъявляться повышенные требования в таком компоненте, как сложно-координационные действия, скорость игровых перемещений теннисистов, что во многом может быть обеспечено за счет роста уровня его координационной и скоростносиловой подготовленности с одновременным повышением эффективности ударных действий.
\end{abstract}

Ключевые слова: юные теннисисты, соревновательная деятельность, основные тенденции развития тенниса, параметры, факторы.

Для цитирования: Мингалимова А.Р., Мутаева И.Ш.*, Коновалов И.Е., Гизатуллина Ч.А. Аспекты эффективности и успешности соревновательной деятельности теннисистов. Педагогикопсихологические и медико-биологические проблемы физической культуры и спорта. 2020; 15(4): 13-20. DOI: 10.14526/2070-4798-2020-15-4-13-20

\section{Aspects of competitive activity effectiveness and success among tennis players}

Albina R. Mingalimova ${ }^{1}$, Ilsiyar Sh. Mutaeva ${ }^{*}$, Igor E. Konovalov ${ }^{1}$, Chulpan A. Gizatullina ${ }^{3}$ ${ }^{1}$ Volga Region State Academy of Physical Culture, Sport and Tourism

Kazan, Russia 


\author{
ORCID: oooo-ooo3-4479-2794 albinausmanova@rambler.ru \\ ORCID: oooo-ooo3-2953-1975, igko20o6@mail.ru \\ ${ }^{2}$ Yelabuga Institute (branch) of Kazan (Volga Region) Federal University \\ Yelabuga, Russia \\ ORCID: oooo-ooo2-9387-7033, mutaeva-i@mail.ru* \\ ${ }^{3}$ Naberezhnye Chelny State Pedagogical University \\ Naberezhnye Chelny, Russia \\ ORCID: oooo-0oo2-8563-3207, mutaeva-ma@yandex.ru
}

\begin{abstract}
The article considers theoretical and practical aspects of competitive training organization in young tennis players. Tennis development as a kind of sport is accompanied by implacable increase of the international rivalry during the competitions of different levels. We underline this kind of sport staginess and popularity increase in children and teen-agers. Tennis attracts youth with the help of an effective speed technique and demand for many-sided physical training. The main tendency of modern tennis development is characterized from the position of technical and tactical techniques in the game development. The effectiveness and the need for speed game increase. At the same time the development of game tactics continues on the basis of the existing technical-tactical actions improvement. Research methods. Information sources analysis, questionnaire survey among the specialists in order to reveal the main factors. They define the effectiveness of tennis players' competitive training. We organized pedagogical observation over the game of highly-qualified tennis players with technical and tactical actions registration into the register. We defined the peculiarities of the training lessons organization, players' activity and efficiency during the game and the number of technical -tactical actions. Results. Theoretical analysis showed the dependence of tennis players' effectiveness during the competitions on the speed and tempo of the game during great volume of technical-tactical actions fulfillment. The important parameters of tennis players' competitive activity are defined. The effectiveness of technical-tactical actions in tennis players' competitive activity is presented in the dynamics of several sports seasons. We also revealed the main factors. They are to be taken into consideration while training young tennis players. Conclusion. For a successful competitive activity a tennis player has to meet the requirements in such component as difficultcoordinating actions, tennis players' speed of game movements. It can be provided owing to the level of his coordinating and speed-power oriented readiness increase with a simultaneous effectiveness increase of the striking actions.
\end{abstract}

Keywords: young tennis players, competitive activity, main tendencies of tennis development, parameters, factors.

For citation: Albina R. Mingalimova, Ilsiyar Sh. Mutaeva, Igor E. Konovalov, Chulpan A. Gizatullina. Aspects of competitive activity effectiveness and success among tennis players. Russian Journal of Physical Education and Sport. 2020; 15(4): 13-20. DOI: 10.14526/2070-4798-2020-15-4-13-20

\section{ВВЕДЕНИЕ}

Теннис является элитным и популярным видом спорта, где противоборствуют либо два игрока, либо две команды участников в парной игре. Международная федерация тенниса является крупной структурой международного уровня, которая объединяет около 205 национальных федераций.

Теннис - это один из видов спорта, направленных на проявление множества двигательных действий в стремительнобыстрой и продолжительной по времени игре. Тенденции развития современного тенниса можно охарактеризовать универсализацией игры. Такой теннис обусловлен необходимостью сочетать активные атакующие действия игрока у сетки со столь же активной игрой на задней линии, а также контролем силы и точности ударов, развитием координационных способностей, возрастанием темпа игры. Для успешного ведения соревновательной деятельности к игрокам предъявляются высокие требования в таких аспектах, как сложно-координационные действия, скорость игровых перемещений теннисистов, что во многом может быть обеспечено за счет роста уровня его координационной и скоростносиловой подготовленности с одновременным повышением эффективности ударных действий.

Анализ научно-методической 
литературы по вопросам подготовки теннисистов показал, что при сравнении напряжённости и результативности международныхсоревнований по теннису в 90-е годы и в настоящее время явно выражена разница в спортивной подготовке. Прежде всего отмечена разница в ускорении темпов и качества игры, осуществляемой за счет оптимизации соревновательной деятельности на основе моделирования динамики состязания и повышения эффективности комплексного развития физических качеств теннисистов $[1,2,3,5,6]$.

Специалистами подчеркнута значимость математического моделирования игры в обучающем процессе юных теннисистов[1,4,6,7]. Отмечено, что повысился класс игры у ведущих команд по теннису за счет повышения мастерства игроков. Это связано прежде всего с увеличением количества соревнований различного уровня, улучшением инвентаря и покрытия. Многие международные игры заканчиваются ничьей или плотным результатам команды-победителя на один мяч. Иногда невозможно определить изъяны в технике ввиду повышения скорости игры каждый год приблизительно на 3-5 \%. Специалисты связывают это с повышением технико-тактического мастерства игроков. Тем не менее респонденты на первые места поставили технико-тактическое мастерство игроков как основу проявления активности и эффективности соревновательной деятельности $[8,9,10,11]$.

Увеличение соревнований и расширение международных встреч обеспечили выявление возможностей для развития данного вида спорта. Отнести теннис к массовым видам спорта не удается, так как для него необходимы спортивные корты с определёнными требованиями по правилам соревнований. В Казани в период проведения Универсиады-2013 заложена хорошая основа для развития тенниса среди различных возрастных групп.

Проведение научно-практических конференций с приглашением зарубежных специалистов дает толчок для научного обоснования методики подготовки в теннисе. Однако мало внимания уделяется отбору и начальной специализации детей и подростков в теннисе $[6,8,9,10,11]$. Требуются научно обоснованные методики подготовки, привлечение различных ресурсов для повышения массовости данного вида спорта. Только увеличение количества занимающихся даст возможность подготовки спортивного резерва для сборных команд республики и страны.

\section{МАТЕРИАЛЫ И МЕТОДЫ}

Исследования проводилась на базе МБУ ДО ЕМР РТ СШ «Олимп» г. Елабуги. В исследовании приняли участие спортсменытеннисисты различных возрастных тренировочных групп и специалисты. Проведен анализ-научно-методической литературы по изучению основных тенденций развития современного тенниса в стране и в мире. Изучены факторы, влияющие на эффективность спортивной подготовки в теннисе. Проведен анкетный опросспециалистов с цельювыявления основных факторов, необходимых для учета в процессе подготовки юных теннисистов. Проведено педагогическое наблюдение за матчами высококвалифицированных теннисистов с записью в журналах, мнений об играх, особенностях проведения тренировочных занятий с целью выявления основных характеристик соревновательной деятельности теннисистов. Определено количество техникотактических действий за игру, активность и эффективность технико-тактических действий игроков. Выявлена структура тренировочных занятий в зависимости от направленности и этапа подготовки теннисистов. Наблюдение проходило в течение одного календарного года. Собраны данные объема и интенсивности тренировочных нагрузок. Для регистрации основных компонентов соревновательной деятельности теннисистов использовали видеосъёмку.

Полученные результаты необходимы для обоснования и разработки экспериментальной методики.

В качестве основных критериев оценки освоенности технико-тактических действий 
теннисистами эксперты использовали:

- оценку степени освоенности технических действий;

- оценку техники выполнения техникотактических действий;

- оценку эффективности и активности использования технических действий за одну игру.

Для определения согласованности мнения экспертов по вопросам выявления и определения значимости основных параметров соревновательной деятельности теннисистов был вычислен коэффициент Кендаля ( К= 0,67 при уровне статистической достоверности $\mathrm{p} \leq$ o,000).

\section{РЕЗУЛЬТАТЫ И ОБСУЖДЕНИЕ}

Проведенный анализ результатов соревнований по теннису позволил выявить основные параметры, характеризующие эффективность соревновательной деятельности теннисистов. Выявление основных параметров соревновательной и тренировочной деятельности высококвалифицированных спортсменов могжет дать важную информацию для определения основных тенденций развития юношеского спорта.

Проведена оценка освоенности техникотактических действий теннисистами. Оценена степень освоенности технических действий; техника выполнения технико-тактических действий; эффективность и активность использования технических действий за одну игру.

На рисунке 1 представлена эффективность технико-тактических действий в соревновательной деятельности теннисистов в

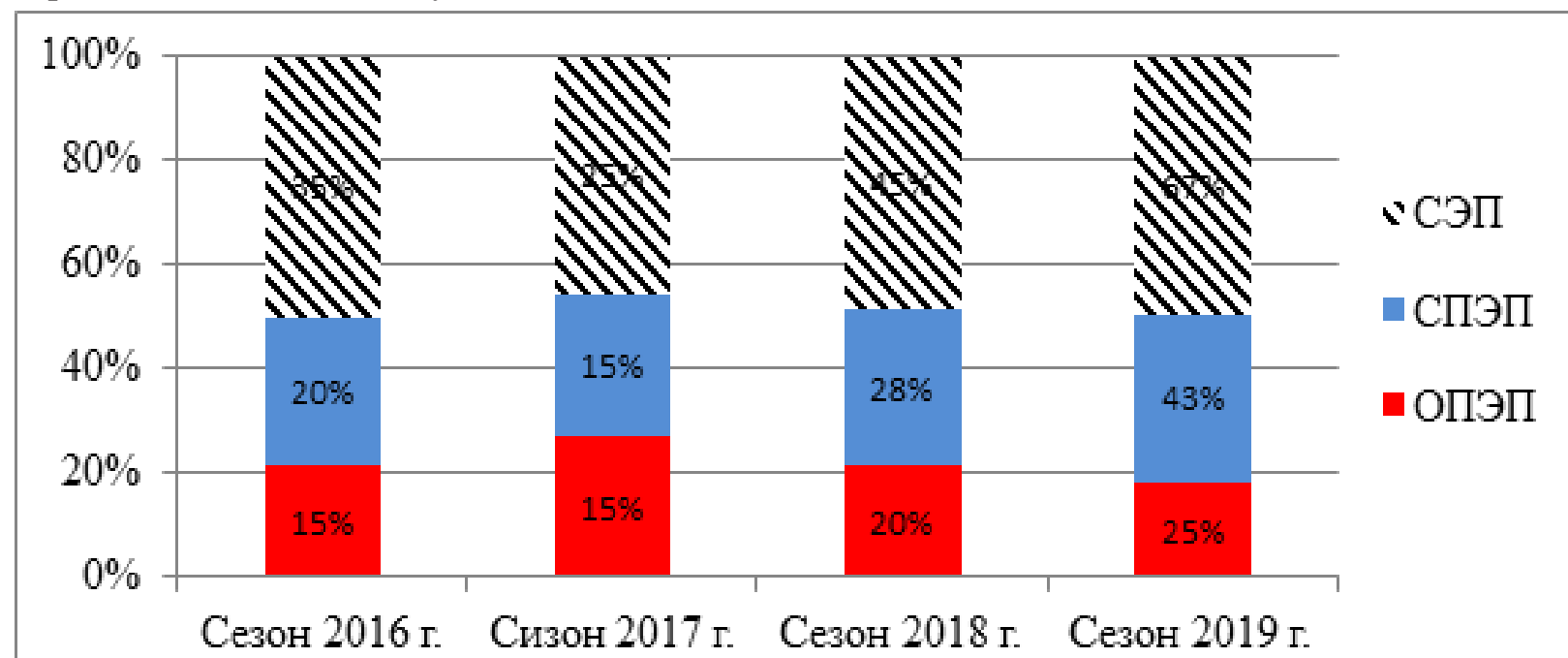

Условные обозначения: СЭ - соревновательный этап подготовки; СПЭП - специально-подготовительный этап подготовки; ОПЭП - обще-подготовительный этап подготовки

Рисунок1-Динамикапоказателейэффективноститехнико-тактическихдействийвсоревновательной деятельности теннисистов в течение четырех спортивных сезонов

Игровая активность и эффективность соревновательной деятельности теннисистов зависят от возраста и квалификации спортсмена. Многолетнее педагогическое наблюдение в ходе официальных игр юношей различной квалификации показало, что результативность соревновательной деятельности зависит прежде всего от количества выполняемых технических действий, а также от эффективности выполнения основных технико-тактических действий.

Показатели активности и эффективности игры теннисиста могут меняться и зависеть от этапов подготовки (рисунок 1). Их соотношение в одном сезоне может меняться, но необходимо стремиться к повышению эффективности каждого используемого технического действия.

В таблице 1 представлены основные параметры, характеризующие эффективность соревновательной деятельности теннисистов. Последовательность их по значимости представлена с учетом мнения пяти экспертов, специалистов спортивной школы городов Нижнекамска, Елабуги и Набережных Челнов. 
Таблица 1 - Определение значимости основных параметров соревновательной деятельности теннисистов (сезоны 2015-2018 гг.)

\begin{tabular}{|l|l|}
\hline \multicolumn{1}{|c|}{ Показатели } & $\mathrm{M} \pm \mathrm{S}$ \\
\hline 1.Активность и эффективность атакующих действий у сетки и на задней линии & $1,01 \pm 0,01$ \\
\hline 2. Объем индивидуальных технико-тактических действий & $1,03 \pm 0,04$ \\
\hline 3. Выполнение сложно-координационных действий & $1,05 \pm 0,06$ \\
\hline 4. Техника и скорость подачи & $1,12 \pm 0,03$ \\
\hline 5.Удары слева и справа, с лета & $1,13 \pm 0,09$ \\
\hline 6.Реакция на мяч & $1,20 \pm 0,08$ \\
\hline 7.Точность удара & $1,22 \pm 0,04$ \\
\hline 8.Свеча & $1,31 \pm 0,01$ \\
\hline 9. Резаный удар & $1,33 \pm 0,06$ \\
\hline 10. Психологическая устойчивость & $1,37 \pm 0,07$ \\
\hline 11. Выбор позиции и маневрирование в игре & $1,40 \pm 0,05$ \\
\hline
\end{tabular}

Из таблицы 1 видно, что первое место занимает активность и эффективность атакующих действий в двух позициях -у сетки и на задней линии игры в теннис. Следовательно, успешность соревновательной деятельности зависит от объема двигательных действий, которыми владеет игрок.

Объем индивидуальных техникотактических действий как условие успешной игры находится на втором месте.

Выполнение сложно-координационных действий занимает третье место в списке показателей. Специалисты связывают это с необходимостью умения переключаться в процессе игры на различные действия и позиции. Главный акцент при переходе с этапа начальной подготовки на второй или третий год обучения делается на развитие двигательных умений и навыков, повышению уровня технический подготовленности и развитию сложнокоординационных способностей уделяется меньше внимания. Это положение необходимо учитывать при подготовке спортивного резерва.

Важным компонентом соревновательной деятельности является выполнение технических действий, таких как техника и скорость подачи; удары слева, справа, с лета; реакция на мяч; точность удара и ударных действий; свеча; резаный удар.

\section{Психологическая}

устойчивость заняла десятое место в списке параметров. Психологическая подготовка выступает связующим звеном в интеграции всех видов подготовки. Уровень психологической устойчивости занимает свои прочные позиции с этапа совершенствования спортивного мастерства, так как уверенность и устойчивость к психологической нагрузке и их формирование в процессе спортивной подготовки является важным компонентом повышения физической работоспособности и успешности соревновательной деятельности. А в юношеском возрасте главная мотивация теннисистов играть быстро и выигрывать всегда.

Выбор позиции и маневрирование в игре былодобавленоспециалистами как необходимой компонент для учёта в интегральной подготовке теннисистов.

Таким образом, выявление значимости основных параметров соревновательной деятельности позволило определить, что с первого дня занятий в теннисе обращается внимание на постановку умения владеть соревновательной позицией и соревновательного духа у теннисистов, который за периоды подготовки может проявиться как индивидуальный стиль маневрирования в игре и тактике видения игры. Данный подход требует учета в процессе начального обучения детей и подростков.

Процесс обучения юных теннисистов усложняется тем, что спортсмены хотят играть по-взрослому, проявляя при этом свои индивидуальные технические действия и воспринимая обучение как второстепенный процесс подготовки. Им хочется всегда играть и участвовать. Поправилам в теннисеобучающиеся выступают на соревнованиях не сразу, а лишь 
после третьего года обучения, пройдя подготовку на начальном этапе обучения. На этап начальной подготовки продолжительностью до трех лет зачисляются учащиеся, прошедшие тестирование физической подготовленности и психических свойств личности с выполнением установленных нормативов.

Данный возрастной этап подготовки юных теннисистов становится особенным и требует тщательного изучения всего процесса подготовки.

В группах этапа начальной подготовки к основным задачам относят обучение основным техническим действиям и воспитание физических качеств. Работа в годичных циклах строится тренерами по принципу подготовительного периода. Дети в этом возрасте с трудом выполняют монотонную работу и упражнения. Именно поэтому тренеру очень важно проводить занятия на высоком эмоциональном уровне. На тренировках, помимо общеразвивающих упражнений, необходимо использовать различные подвижные игры с обязательным подведением итогов. В этом возрасте дети наиболее чувствительны к восприятию заданий на быстроту движений, быстроту реагирования, частоту движений, на способность к ориентированию в пространстве, на задания по перестроению двигательных действий, ритму. Упражнения и задания по воспитанию этих качеств должны быть непродолжительными и разнообразными. На этапе начальной подготовки первого и второго годов обучения необходимо обращать внимание на интерес, проявляемый учащимся к занятиям в секции тенниса, на быстроту обучаемости во время занятий подвижными играми, мотивацию, моральные качества, психологическую устойчивость, координационные способности, физическую выносливость и быстроту восстановления. На третьем году обучения решаемые задачи расширяются. Например, при воспитании физических качеств учащихся продолжает делаться акцент на воспитание аэробной (общей) выносливости. Это важно еще и потому, что у детей очень низкий процент использования кислорода (7 лет - 3\%, 10 лет -
3,6\%, 14 лет - 3,9\%), относительно невысокая экономичность функций внешнего дыхания и транспортной функции крови, и именно поэтому низкая способность переносить гипоксические состояния.

Под координационными способностями принято понимать способность осваивать двигательные действия, преобразовывать двигательные действия и переключаться от одних двигательных действий к другим.

Координационные способности зависят в основном от функций центральной нервной системы, а также анализаторов, особенно двигательного кинестетического, от имеющегося опыта, касающегося освоения движения и количества уже освоенных движений, от восприятия собственных движений и окружающей обстановки, инициативности, находчивости.

Установлена тесная связь между координационными способностями и быстротой и точностью сложных двигательных реакций.

На тренировочных занятиях этапа начальной подготовки внимание теннисистов необходимо акцентировать на перемещении рук, плеч, частей тела, ног и их последовательности во время выполнения всех элементов ударного действия. Акцент обязательно должен быть сделан на развиваемые при этом усилия одних групп мышц и расслабление других. Необходимо, чтобы спортсмен мог мысленно воспроизвести основныехарактеристикивсехударныхдействий. Применение идеомоторной тренировки во время тренировочных занятий может оказать большую помощь в развитии ударных действий. Благодаря таким занятиям спортсмен может лучше усвоить оптимальный ритм движений при выполнении ударных действий. Большое значение для совершенствования чувства ритма имеет применение на занятиях музыки, элементов фитнеса: аэробики, степ-аэробики. Н.Г. Озолин (1970) отмечал, что «подчинение спортсмена ритму музыки значительно облегчает...выполнение ...работы», музыкальное сопровождение играет роль ритмолидера, и его целесообразно применять при использовании обще-подготовительных упражнений. 


\section{Заслуженный тренер $\mathrm{CCCP}$ H.C. применялись занятия аэробикой.}

Теплякова большое значение придавала чувству Специально подобранная музыка ритма, акцентируя внимание на фазе активности и паузе при выполнении удара. В подготовке своих воспитанников она использовала элементы балета для совершенствования чувства ритма. Мнение Н.С. Тепляковой разделяла и заслуженный тренер СССР Л.Д. Преображенская (1998), считавшая, что танцы имеют большое значение в подготовке теннисистов. В 1980-годы, когда старшим тренером сборной команды СССР был Ш.А. Тарпищев, в подготовке теннисистов во время выполнения определённых заданий положительно сказывается на совершенствовании чувства ритма, столь необходимого для теннисиста.

На основе проведенного анализа и обобщения результатов педагогического наблюдения и экспертной оценки выявлены факторы, определяющие успешность подготовки юных теннисистов.

Таблица 2 - Факторы, определяющие успешность и эффективность подготовки юных теннисистов (сезоны 2016-2018 гг.)

\begin{tabular}{|c|c|}
\hline Факторы & $\mathrm{M} \pm \mathrm{S}$ \\
\hline Упражнения, приближенные к соревновательной деятельности теннисистов & $1,01 \pm 0,03$ \\
\hline Упражнения легко-координационной направленности & $1,02 \pm 0,05$ \\
\hline Упражнения сложно-координационных действий & $1,11 \pm 0,08$ \\
\hline Упражнения, повышающие скорость подачи мяча & $1,13 \pm 0,05$ \\
\hline Упражнения, совершенствующие удар слева, справа и с лета & $1,15 \pm 0,11$ \\
\hline Упражнения индивидуализированной направленности & $1,17 \pm 0,08$ \\
\hline Упражнения для совершенствования точности удара по мячу & $1,25 \pm 0,04$ \\
\hline Упражнения, повышающие интенсивность тренировочных воздействий & $1,27 \pm 0,01$ \\
\hline $\begin{array}{l}\text { Упражнения, повышающие } \\
\text { психологических нагрузок }\end{array}$ & $1,29 \pm 0,11$ \\
\hline
\end{tabular}

Все причисленные в таблице 2 средства требуют экспериментального обоснования с разделением их реализации по этапам обучения теннисистов. Для этого требуется создание специализированной классификации техники тенниса для распределения средств по сложности выполнения по отдельности и в комплексе по годам обучения.

На основе учета естественных закономерностей развития физических качеств обеспечиваются наиболее значительные темпы прироста определённых способностей теннисистов, и это создает благоприятные условия для формирования технико-тактических действий различной сложности и усвоения информации, необходимой для успешности соревновательной деятельности.

\section{ЗАКЛЮЧЕНИЕ}

Таким образом, для ведения успешной соревновательной деятельности к теннису предъявляются повышенные требования в таких компонентах, как сложнокоординационные действия, скорость игровых перемещений теннисиста, что во многом может быть обеспечено за счет роста уровня его координационной и скоростносиловой подготовленности с одновременным повышением эффективности ударных действий. Теоретический анализ показал, что основными критериями высокой физической подготовки юных теннисистов являются координационная и скоростно-силовая подготовка с одновременным повышением эффективности ударных действий и правильной техники. Этап начальной 
подготовки юных теннисистов становится особенным и требует тщательного изучения всего процесса подготовки.

На тренировочных занятиях этапа начальной подготовки внимание теннисистов необходимо акцентировать на перемещении рук, плеч, частей тела, ног и их последовательности во время выполнения всех элементов ударного действия. Большую помощь в этом отношении может оказать применение идеомоторной тренировки, благодаря которой спортсмен может лучше усвоить оптимальный ритм движений при выполнении ударных действий. Большое значение для совершенствования чувства ритма имеет применение музыки на занятиях, занятия с применением элементов фитнеса: аэробика, степ-аэробика.

\section{СПИСОК ЛИТЕРАТУРЫ}

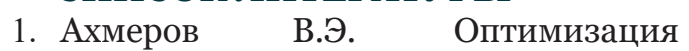
соревновательной деятельности квалифицированных теннисистов на основе моделирования динамики состязания: автореф. дис. ... канд. пед. наук. Минск. 2005: 17-18

2. Волков Л.В. Физические способности детей и подростков. М.: Медиа. 2012: 119.

3. Голенко В.А., Скородумова А.П., Тарпищев Ш.А. Академия тенниса. М.: Дедалус. 2002: 237.

4. Лаптев А.А. Структура движений при подаче в теннисе, методические предпосылки ее формирования и совершенствования: дис. ... канд. пед. Наук. М. 2007: 178.

5. Скородумова А.П., Баранов И.С.,
Кузнецова О.В., Семенова С.Д. Контроль физической подготовленности теннисистов 6-14 лет. М. 2018: 64.

6. Батищев В.И., Разумов Д.В. Математическоемоделированиеикомпьютерная графика в обучающем процессе юных теннисистов. Стимулирование мотивации творческого развития личности: психологопедагогические аспекты : сборник статей и тезисов Второй Всероссийской научнопрактической конференции. Набережные Челны. 2004: 42.

7. Камалиева Г.А., Кузнецова 3.M. Модель подготовки волейболистов к преодолению препятствий и трудностей, неожиданно возникающих в соревновательной деятельности. Педагогико-психологические $и$ медико-биологические проблемы физической культуры и спорта. 2011; 2(19): 38-44.

8. Кузнецов А.С., Кузнецова 3.М. II Съезд членов общественной организации «Российское профессорское собрание». Педагогикопсихологические и медико-биологические проблемы физической культуры и спорта. 2019. 14(4), 5-7. DOI: 10.14526/2070-4798-2019-14-4-57.

9. Crocker P.R.E., Mosewich A.D., Kowalski K.C., Besenski L.J. Coping: Research design and analysis issues. Coping on sport: Theory, methods, and related constructs. 2010: 53-76.

10. Gaudreau P., Blondin J.P. Development of a questionnaire for the assessment of coping strategies employed by athletes in competitive sport settings. Psychology of Sport and Exercise. 2002; 3: 1-34.

11. Puente Diaz, Anshel M.H. Sources of acute stress, cognitive appraisal, and coping strategies among of trait emotional intelligence. Cognition and Emotion. 2007; 21: 26-55.

\section{Статья поступила в редакцию: 20.11.2020}

Мингалимова Альбина Рауфовна - аспирант; Поволжская государственная академия физической культуры, спорта и туризма, Россия, г. Казань, Деревня универсиады, дом 35, е-таіl: albinausmanova@rambler.ru

Мутаева Ильсияр Шафиковна - кандидат биологических наук, профессор; Елабужский институт (филиал) Казанского (Приволжского) федерального университета, 4236оо, Россия, г. Елабуга, ул. Казанская, дом 89, e-mail: mutaeva-i@mail.ru

Коновалов Игоръ Евгенвевич - доктор педагогических наук, доцент кафедры теории и методики волейбола и баскетбола; Поволжская государственная академия физической культуры, спорта и туризма, Россия, г. Казань, Деревня универсиады, дом 35, e-mail: igko2006@ mail.ru

Гизатуллина Чулпан Анасовна - кандидат педагогических наук, доцент; Набережночелнинский государственный педагогический университет, 423806, РТ, г. Набережные Челны, ул. им. Низаметдинова, дом 28, e-mail: mutaeva-ma@mail.ru 